EDITORIAL

\title{
Urbanization in the Anthropocene: inaugural npj Urban
} \section{Sustainability}

npj Urban Sustainability (2021)1:7; https://doi. org/10.1038/s42949-021-00019-9

This is the inaugural editorial of npj Urban Sustainability. This new journal seeks to inspire an evidence-based and globally oriented conversation on the importance of urban issues for our planet's future. In that, npj Urban Sustainability will address some of the most challenging questions humanity has ever faced. It will investigate how urban regions around the world could radically transform to ensure global sustainability. The aim of the journal is to focus on how cities and their regions are reshaping to meet major economic, social, and environmental challenges, developing new pathways to sustainable urbanization.

The journal has an intentionally very wide audience of urban scholars, policy makers, and practitioners and welcomes critical studies, comparative case studies, and impact studies, including policy solutions for existing cities and regions. At the onset, and of course leaving an open door to urban creativity and innovative city research, npj Urban Sustainability seeks to focus on three major drivers of the conversation on the global role of cities.

First, while encouraging a global conversation on the place of urban processes in sustainability, we will encourage submissions from researchers studying urbanization in the Global South. It is now evident for many practitioners and scholars that much of the future of urbanization and its associated challenges, opportunities, and innovation will depend on the Global South. This is both because of the sheer importance of the urban trends emerging in these realities and also because of the innovations and perspectives that can come from Southern perspectives and investigations. Therefore, rapidly expanding knowledge for, of, and most importantly with the global south is an urgent imperative for sustainability science. Empirical and theoretical analyses of the implications of urban change in relation to inequality will be especially welcome.

Second, the interplay of urbanization, climate change, and the biodiversity crisis are also highlighted themes for us. Urban systems, because of their concentration of people and infrastructure, create risks to disturbances from climate change or other challenges. Additionally, the design of cities concentrates heat, traps air pollutants, and creates a number of environmental problems that affect human health and well-being in cities. Urban systems cannot be themselves fully sustainable and are rather dependent on other systems and especially rural landscapes to provide natural resources, food, energy, and water that are the raw materials for human societies on an urban planet. Global environmental changes, such as global biodiversity decline, accelerating climate change, depleting soil productivity for food production, and more, have knock-on impacts for cities and continued urbanization.

Third, we also strongly encourage submission of papers on the role of data and innovation in urban research. This is both from the perspective of integration of innovative technology and solutions that emerge from collection and analyses of urban data and case studies, including both large and fine-grained spatial and temporal data, as well as from case studies that seek to recast the boundaries of urban research for planetary sustainability.
These three strands of research, and other discussions within the remit of the journal, come however at a particular political-economic juncture. npj Urban Sustainability aims to not only present the latest science to drive sustainable urbanization but also it wants to do so explicitly in dialogue with today's most pressing international agendas. In doing so, it welcomes interventions that intersect with a key question: where are we at with global urban governance? A world of cities needs a world politics fit for those cities-a key conversation that pits the contemporary multilateral system in dialogue with, if not at times against, cities and urban processes. We also encourage submission of papers that make critical reflections on what has happened since the decisions were taken on the United Nations Sustainable Development Goals (SDGs), and their explicit acknowledgement of urban issues, and New Urban Agenda. Here we specifically prioritize research related to the SDG 11 (make cities and human settlements inclusive, safe, resilient, and sustainable), and how this goal interacts with the other SDGs in urbanization processes.

However, we aim to do so by taking a cross-sectorial view of sustainability that does not disregard or overshadow other thematic global agendas in their potential to uplift the sustainable future of an urban planet.

This first inaugural issue has the theme "Urbanization in the Anthropocene." It is introduced by a Comment ${ }^{1}$ setting out some of the dimensions of how urbanization may not only accelerate the global processes underlying the Anthropocene but also how cities and urban regions may be a positive force in contributing to a "good" Anthropocene ${ }^{2}$. The set of papers highlight both challenges and opportunities of cities and urban regions in forming a more resilient sustainable future addressing demography $^{3}$ (Kii et al.), biodiversity ${ }^{4}$ (Oke et al.), climate change ${ }^{5,6}$ (Solecki et al., Norman et al.), infrastructure ${ }^{7}$ (Chester et al.) particularly water $^{8}$ (Derrible et al.), and how to mobilize knowledge and science for sustainability ${ }^{9}$ (Zhou et al.), giving perspectives on coproduction in data-scarce circumstances in the global south ${ }^{10}$ (Croese et al.).

In the coming issues, we will strive to encourage broad perspectives on localized implementation of a number of global policy initiatives, either from the perspective of the overall 2030 Agenda of the United Nations or within specific domain statements like the Sendai Framework on disaster risk reduction, the Addis Ababa Action Agenda on financing sustainable development, or indeed the Paris Agreement on climate change. In fact, the launch of npj Urban Sustainability comes at a time where consideration of urban issues in global agendas is again of possibly pivotal importance. It follows not only a "cities" recognition by the UN Framework Convention on Climate Change and Intergovernmental Panel on Climate Change but also similar movements in global health and migration, and it foreshadows a growing push for an equal recognition within the realm of global biodiversity governance. How has the UN system so far dealt with the urban age? What are the strategic plans for the future? What institutional reforms are needed? How have nations and cities progressed? What are short- and long-term consequences of coronavirus disease 2019 on urban development? What are the significant examples of successfully initiated implementation processes? What have been the main obstacles and barriers to 
transformations for urban sustainability? What can perspectives, new methods, and voices from the global south do to drive and recast this conversation?

We believe that, in a time of pressing urban questions of a global nature, the best urban science needs to have a stake in its tangible implications and the major international exchanges that are set to shape the very cities this research engages with.

Received: 11 January 2021; Accepted: 19 January 2021; Published online: 23 February 2021

Thomas Elmqvist ${ }^{1 凶}$, Michele Acuto ${ }^{2}$, Pippin Anderson ${ }^{3}$ Larissa Larsen ${ }^{4}$, Timon McPhearson ${ }^{1,5,6}$ and Xiaoling Zhang ${ }^{7,8}$ ${ }^{1}$ Stockholm Resilience Centre, Stockholm University, Stockholm, Sweden. ${ }^{2}$ Connected Cities Lab, Faculty of Architecture, Building and Planning, University of Melbourne, Parkville, VIC 3010, Australia.

${ }^{3}$ Department of Environmental and Geographical Science, University of Cape Town, Cape Town, South Africa. ${ }^{4}$ Taubman College of Architecture and Planning, University of Michigan, Ann Arbor, MI, USA. ${ }^{5}$ Urban Systems Lab, The New School, New York, NY, USA. ${ }^{6}$ Cary Institute of Ecosystem Studies, Millbrook, NY, USA. ${ }^{7}$ Department of

Public Policy, City University of Hong Kong, Kowloon Tong, Hong Kong, China. ${ }^{8}$ Shenzhen Research Institute, City University of Hong Kong, Shenzhen, China. ${ }^{\circledR e m a i l: ~ t h o m a s . e l m a v i s t @ s u . s e ~}$

\section{REFERENCES}

1. Elmqvist, T. et al. Urbanization in and for the Anthropocene. npj Urban Sustain. https://doi.org/10.1038/s42949-021-00018-w (2021).

2. McPhearson, T. et al. Radical changes for transformations to a good Anthropocene. npj Urban Sustain. https://doi.org/10.1038/s42949-021-00017-x (2021).

3. Kii, M. et al. Projecting future populations of urban agglomerations: around the world and through the 21st century. npj Urban Sustain. https://doi.org/10.1038/ s42949-020-00007-5 (2021).

4. Oke, C. et al. Cities should respond to the biodiversity extinction crisis. npj Urban Sustain. https://doi.org/10.1038/s42949-020-00010-w (2021).

5. Solecki, W. et al. Climate research and action in cities through advanced sciencepolicy-practice partnerships. npj Urban Sustain. https://doi.org/10.1038/s42949021-00015-z (2021).

6. Norman, B. et al. Apocalypse now: Australian bushfires and the future of urban settlements. npj Urban Sustain. https://doi.org/10.1038/s42949-020-00013-7 (2021).
7. Chester, M. et al. Infrastructure resilience for acceleration, uncertainty, and complexity in the Anthropocene. npj Urban Sustain. https://doi.org/10.1038/ s42949-021-00016-y (2021).

8. Derrible, S., Truong, T. T. M., Pham, H. T., Nguyen, Q. H. Learning from Hanoi for the future of water distribution. npj Urban Sustain. https://doi.org/10.1038/ s42949-020-00001-x (2021).

9. Zhou, W. et al. Conceptual frameworks facilitate integration for transdisciplinary urban science. npj Urban Sustain. https://doi.org/10.1038/s42949-020-00011-9 (2021).

10. Croese, S. et al. Co-producing urban knowledge in Angola and Mozambique: towards meeting SDG 11. npj Urban Sustain. https://doi.org/10.1038/s42949-02000006-6 (2021).

\section{COMPETING INTERESTS}

The authors declare no competing interests.

\section{ADDITIONAL INFORMATION}

Correspondence and requests for materials should be addressed to T.E.

Reprints and permission information is available at http://www.nature.com/ reprints

Publisher's note Springer Nature remains neutral with regard to jurisdictional claims in published maps and institutional affiliations. c) (i)

Open Access This article is licensed under a Creative Commons Attribution 4.0 International License, which permits use, sharing, adaptation, distribution and reproduction in any medium or format, as long as you give appropriate credit to the original author(s) and the source, provide a link to the Creative Commons license, and indicate if changes were made. The images or other third party material in this article are included in the article's Creative Commons license, unless indicated otherwise in a credit line to the material. If material is not included in the article's Creative Commons license and your intended use is not permitted by statutory regulation or exceeds the permitted use, you will need to obtain permission directly from the copyright holder. To view a copy of this license, visit http://creativecommons. org/licenses/by/4.0/.

(c) The Author(s) 2021 